\title{
Key criteria of ERP/CRM systems selection in SMEs in Poland
}

\author{
Małgorzata Cieciora, Faculty of Information Management, Polish-Japanese Academy of \\ Information Technology, Poland, Malgorzata.Cieciora@pja.edu.pl
}

Wiktor Bołkunow, Collegium of Management and Finance, Warsaw School of Economics, Poland,wbolk@sgh.waw.pl

Piotr Pietrzak, Management Institute, Warsaw University of Life Sciences, Poland, Piotr Pietrzak1@sggw.pl

Piotr Gago, Faculty of Computer Science, Polish-Japanese Academy of Information Technology, Poland, pgago@pja.edu.pl

\begin{abstract}
The purpose of this paper was to conduct an investigation on criteria of Enterprise Resources Planning (ERP)/Customer Relations Management (CRM) systems selection used by Small and Medium-sized Enterprises (SMEs) in Poland. The main goal was to define the key selection criteria that should be used to ensure the optimal decision of the purchase of the system. The reason for the choice of this research question was that SMEs have to constantly struggle with lack of resources. The choice of the right ERP and/or CRM system can significantly improve their operational efficiency and competitiveness. A synthetic review of the literature on the selection criteria of ERP and/or CRM systems was conducted and presented. Opinions of 83 respondents with work experience in SMEs that had undergone an implementation of an ERP and/or CRM system or vendors of ERP and/or CRM systems for SMEs in Poland were collected in the form of Google Form surveys and analyzed with the use of Spearman's rank order correlation. The main conclusion of this study is that two most important selection criteria are: system functionality and the ability to ensure data security. The study results may be of practical use for SMEs' decisionmakers for the selection of the CRM and/or ERP class system. A further and more comprehensive research into the topic is recommended.
\end{abstract}

Keywords: Customer Relations Management (CRM), Enterprise Resources Planning (ERP), Information and Communication Technology (ICT), Small and Medium-sized Enterprises (SMEs), Poland.

\section{Introduction}

In the times of the Knowledge Based Economy and the dynamic development of Information and Communication Technologies (ICT), the use of computer-aided management tools has become a necessity for most companies. Two popular types of software are Customer Relationship Management (CRM) and Enterprise Resource Planning (ERP) systems. A CRM system, supports and regulates the management of contacts as well as relationship with clients. It is a technical tool 
for implementing the management's strategy, in which the main emphasis is placed on building a long-term relationship with the clients and to gain their loyalty. The essence of the CRM system is to gather in one place and organize all procedures related to contacts with clients, at each stage of the so-called sales funnel, i.e. the path a potential customer must follow from the first contact with the brand until the purchase of the product. The ERP system is more extensive and ensures the integration of all organizational activities, streamlining information flow, and simplifying business processes. The latest versions of ERP also allow one to work in the network, access via web browsers, have the functionality to manage customer contacts, i.e. CRM, Business Intelligence (BI) analytical tools, as well as the ability to create websites with access for customers and business partners. In general, ERP systems allow changes to be made in real time, and all necessary data is available when making decisions. The purchase and use of such tools can, therefore, significantly increase the efficiency of the company's operations, in particular when considering the fact that both competitors, as well as customers and other company's stakeholders, often use these systems. For Small and Medium-sized Enterprises (SMEs), though, the purchase and implementation of this type of software is still quite a challenge, mainly due to the lack of sufficient resources, both financial and human. It is worth noting that they still have significantly lower Digital Intensity Index (DII) than big companies. DII is an indicator used by Eurostat to measure the digital maturity of companies, whose components include the use of ERP and CRM software. According to Statistics Poland (GUS), only $11.7 \%$ of SMEs had high or very high digital intensity in 2017, in comparison to $40.2 \%$ of big companies (GUS, 2017, p. 113). The main barriers include, among others, lack of ICT expertise of SME owners (Stankovska et al., 2016), which may result in problems with the selection of the right systems, as it requires specialist analysis of the company's needs and obtaining reliable and complete information on the costs and usability of solutions offered on the market. Therefore, determining the appropriate selection criteria for ERP and CRM systems for SMEs in Poland should be considered an important research question. However, there are also other ICT systems that support decision-making system or process management in companies. The selection of the two systems for this study was based primarily on the fact that they were chosen as the key indicators tracking digitization processes of EU28 enterprises in the aforementioned DII used by Eurostat (2018).

The aim of this study was to define the main criteria which could be used during the process of selection of the appropriate ERP and CRM systems within SMEs in Poland. First, a brief literature review on the selection criteria of ERP and CRM systems in SMEs is presented. We developed survey questionnaire following the literature review. The questionnaire (attached in the Appendix) was validated on a sample of six academic teachers with practical experience in ERP and/or CRM implementation. Next, data was collected from 83 IT specialists with experience in ERP and CRM systems implementation and workers of Polish SMEs which implemented such systems, which the results are presented and discussed. This paper ends with a summary and conclusions.

\section{Literature Review}

There is a considerable amount of academic literature on digitalization of companies of various sizes. The brief literature review of this paper is divided into two main separate parts - one focusing on the ERP class system selection by SMEs and the other one devoted to the CRM class system 
selection by SMEs, as most of the literature on the subject have concentrated on issues connected with the selection or implementation of one of the aforementioned IT systems exclusively.

As far as the selection of ERP systems is concerned, according to Alanbay et al. (2005), the choice of the ERP system should be based on a long-term business strategy of the organization because the ERP system is the "information backbone of an organization and reaches into all areas of the business and value-chain" (p. 2). The selection should be made on the basis of the needs of the company, which would determine the choice of modules. Other selection criteria include: customization (the software should be adaptable to the company's needs, but "shouldn't cause difficulties in updating to future software releases" (Alanbay et al., 2005, p. 2)), relative ease of implementation and maintenance ("whenever an add-on procedure or a patch is available, it can be updated immediately" (Alanbay et al., 2005, p. 2)), real time changes, flexibility ("as the business requirements of the organization change, it should be possible to add extra modules" (Alanbay et al., 2005, p. 2)), user-friendliness, cost (which is a very important criterion especially in the case of SMEs), system requirements, after sales support and training, back-up system, reporting and analysis features, vendor credentials, integration with other software/applications, Internet integration and financing options (Alanbay et al., 2005, p. 2). According to a literature review conducted by Baki and Cakar (2005), the most important selection criteria of an ERP system include "fit with parent/allied organisation systems, cross module integration, compatibility with other systems" (p. 85).

As far as more recent studies are concerned, research conducted by Czekster et al. (2019) in the form of another extensive literature review showed that the key criteria for the ERP system selection by SMEs are "acquisition and monthly costs, ERP reputation and references, level of support and training, deployment experience, ERP's feature set, easiness of use, efficiency and reliability, and maintainability" (p. 1). They may vary to some extent depending on the country. For example, in Iran the main criteria, grouped under the headings are: Management Factors ("implementation time, cost, vendor reputation, consultancy services, R\&D capability") and Product Factors ("interoperability, reusability, user-friendliness, flexibility, portability, functionality, reliability, usability, maintainability, and efficiency") (Hamidi, 2015; Czekster et al., 2019, p. 8). Studies conducted in Portugal stressed the importance of:

"technical team capability, coverage of the required functionalities norms/regulations, vendor references/portfolio, offered guarantees ..., technical support, documentation, and consultancy services, training services, payment/financial terms, vendor market share/scale, implementation ability, vendor financial conditions, OS compatibility, HW requirements, database engine compatibility, integration with other platforms, source code accessibility, user friendliness ..., SW licensing, HW/infrastructure, integration/ middleware, maintenance, software acquisition, and consultancy, scalability/upgradeability, stability/recovery capacity, security issues, customization." (Cruz-Cunha et al., 2016; Czekster et al, 2019, p. 8)

As far as the main criteria for the selecting a CRM system for SMEs are concerned, according to studies conducted in Hungary, "there were great differences in product selection criteria in the case of various CRM purchasers" (Reicher \& Szeghegyi, 2015, p. 194). The main conclusion that may be drawn from that study was that the final decision was based on the SME's owner's attitude. 
Moreover, quite often the SME owners did not have expertise in the systems (Reicher \& Szeghegyi, 2015).

As a result of the dynamic development of ICT technologies and companies offering these services, one can find in the network many practical guides created by business consultants in the field of ICT, presenting the topic of criteria for selecting ERP/CRM systems for companies from the SME sector. They stress, for example, that one should take into consideration the fact that SMEs are often companies that have grown from family businesses and operate in a very specific way. Their business strategy is based on a very individualized approach to clients, often based on personal ownership relations. It is very important that in such a business model, customers feel that they are important contractors and that all, often personal arrangements are followed. Therefore, the CRM system must allow any modeling of the database structure along with the creation of a number of exceptions and individual arrangements. Moreover, CRM system functionalities for SMEs often have to go beyond book applications. Quite often the CRM system becomes the main database in the company and then the commercial area, although still very important, is only one of the several key functionalities (Murias, 2019). As far as basic functionalities are concerned, all of them must have the following modules:

- Customer card with event history.

- The responsive version that opens on the phone.

- Possibility of giving different rights to the manager and salesman.

- Calendar for planning sales activities.

- The ability to create reports.

- Sales opportunities management module.

- User support (each system has specific support hours) (Murias, 2019).

Additional functionalities or criteria that should be taken into consideration include, e.g. the ease of use, configurability, the amount of time needed to add new items (sales opportunity or a contractor), the number of language versions, integration with other tools, e.g. the e-mail system, calendar or marketing tools and mobile application, (Negacz, 2019). The system should not be expensive. In case of the most popular Software-as-a-Service (SaaS) solutions (i.e. the user pays a fixed monthly fee for using the system, thus, not incurring costs of system maintenance, updating, server or other additional elements), the cost should not exceed 70 PLN (17 Euro) net of rate per user in the cheapest paid version (Negacz, 2019). One should also check the reputation and level of expertise of the software provider, most importantly its history of successful implementations. It is also a good idea to check a free demo version of the system before making a decision on its purchase (QuickCRM, 2019).

One should also remember that in order to buy an optimal CRM system one should first conduct a thorough needs analysis of the SME. If there are not sufficient resources to hire an external consultant, it is advisable to involve the specialists from all company units, not just the company owner, to form the analytical team. They should agree on implementation goals and develop a vision of what the enterprise should look like after implementing the CRM. As there is a large number of software providers, it is a good idea to select several of them for further, closer investigation before making a final choice. The criteria that should be taken into consideration include system functionality (it must be consistent with the company's priority needs), modularity, 
price and expandability (the SME may grow \& need to implement additional elements) (Madar, 2019).

As far as the ERP systems are concerned, there seems to be a problem with a widespread belief that their implementation would be very expensive for a SME, the main problem being the lack of a proper IT system in the company. This problem could be quite easily overcome, though, as there are closed solutions on the market ready for implementation (Jankowski, 2015). It would also be advisable to choose an experienced and reputable ERP vendor who will help with conducting an analysis of the company's needs, as a result of which only the most important modules will be chosen for the implementation (or at least its first stage), which will significantly reduce the time and cost of the implementation. As the cost of buying the license for the system may be a significant barrier for SMEs, they may consider choosing a vendor that offers the option of paying an annual subscription for temporary access to the software instead (Ciski, 2015).

The main findings from both literature reviews devoted to the issues concerned with the selection and implementation of ERP and CRM class systems separately formed together the basis for the survey we designed to address the research question. Although the two systems are different and serve different purposes, they both are Information Technology (IT) systems meant to facilitate the functioning of contemporary companies of various sizes. It means that, firstly, both of them can be useful for SMEs, and secondly, the selection and implementation of either of them can pose a challenge for SME owners, struggling with lack of resources and ICT expertise. The findings from the two literature review sections appear to indicate that a wide array of problems connected with the selection and implementation of the IT system are the same, regardless of whether the system is of the ERP or CRM class and can be broadly summed up as: financial issues, e.g. the price of the system as well as its implementation and maintenance, technical issues, e.g. compatibility with other systems, implementation time, ease of use or security issues and, finally, vendor-related issues, i.e. its reputation, experience and references.

\section{Methodology}

Surveys regarding the criteria for selecting ERP/CRM systems in SMEs in Poland, were carried out from December 7 to December 23, 2019, via the online Google Form. We designed the surveys for this study on the basis of literature review noted above. The selection of the sample was purposeful. The respondents were 83 in total and included: (1) ICT specialists with experience of implementing ERP/CRM systems in SMEs in Poland; or (2) workers of SMEs with experience of implementing ERP/CRM systems in SMEs in Poland. They were graduates and students of the Warsaw School of Economics, Polish-Japanese Academy of Information Technology in Warsaw, Poland, and members of a closed Facebook group created by systems developers 'SysOps/DevOps Polska'. The respondents were asked to evaluate the significance of 14 criteria taken into account when choosing ERP/CRM systems for SMEs, using a 5-point Likert scale. The criteria concerned both the IT system itself and the company implementing it. They included: (1) system functionality, (2) the system's compatibility with other IT systems implemented in companies, (3) the cost of purchasing and implementing the system, (4) system implementation time, (5) system development options, (6) reputation and experience of the system provider, (7) the option of paying an annual subscription instead of purchasing the system, (8) ensuring data security, (9) quality and 
cost of support after implementation, (10) innovation of system, (11) substantive and technological advancement of the system, (12) hardware and infrastructure requirements of the system, (13) ensuring both adaptation to the industry and system versatility and (14) system location.

The criteria used in the survey largely correspond to the guidelines laid down in the ISO/IEC 25010 standard: Systems and software engineering - Systems and software Quality Requirements and Evaluation (SQuaRE) - system and software quality models. According to the document, a good quality IT product should be characterized by "functional suitability, performance efficiency, compatibility, usability, reliability, security, maintainability and portability" (Estdale \& Georgiadou, 2018, p. 494). The results of the surveys were ranked according to the total share of 'important' and 'very important' responses in the respondents' assessment and analyzed with the use of Spearman's rank order correlation.

\section{Results}

Respondents were grouped according to gender, level of education, position/role during the implementation of the ERP/CRM system, and years of experience in the implementation/use of ERP/CRM systems. Men dominated in the study group (75.9\%). People with higher education constituted nearly half of the respondents. Most respondents, about $50.0 \%$, were employees of companies in which the ERP/CRM system was implemented. Technical employees of external companies implementing the system constituted $33.8 \%$ of the research sample. Respondents who were the owners/decision-makers of SMEs in which the system was implemented amounted to $6.3 \%$, while the owners/decision-makers of external companies responsible for the system implementation constituted $3.8 \%$ of the sample. The remaining part of the respondents occupied different positions or had a different role during the implementation of the systems. Among them were: programmers, testers, and system auditors. More than half of the respondents $(\sim 57.3 \%)$ were people with 1 to 5 -years of experience. About $11.0 \%$ of those surveyed had more than 5-years of experience. It is worth mentioning that the SME sector companies in which the respondents were employed were related to education, telecommunications, Fast-Moving Consumer Goods (FMCG), pharmacy, and energy. The data received show that the most important criteria taken into account when choosing ERP/CRM systems in the SME sector are: system functionality (a total of $95.2 \%$ of respondents indicated that this criterion is "important" or "very important"), the ability to ensure data security $(94.0 \%)$ and the quality and cost of support after the implementation of the systems (87.9\%). By contrast, the least important selection criteria when choosing systems are: innovation of the system and the option of paying an annual subscription fee instead of purchasing the system (Table 1).

The next step of the analysis was to check if there are differences in the perception of the criteria between respondents occupying different positions and performing different functions during the implementation of ERP/CRM systems. Therefore, the research sample was divided into two groups: (1) people employed in the companies responsible for system implementation (decisionmakers/owners and technical employees); and (2) people employed in SMEs in which the systems were implemented (decision-makers/owners and technical employees). Respondents who indicated the answer "other" in the section concerning "employment" were excluded from this analysis. 
Table 1. Importance of Criteria Taken Into Account When Choosing the ERP/CRM Class Systems, According to All Respondents [\%].

\begin{tabular}{|c|c|c|c|c|c|c|}
\hline \multirow[t]{2}{*}{ Rank } & \multirow{2}{*}{ Criterion } & \multicolumn{5}{|l|}{ Importance } \\
\hline & & $\begin{array}{l}\text { Completely } \\
\text { unimportant }\end{array}$ & $\begin{array}{l}\text { Not } \\
\text { important }\end{array}$ & $\begin{array}{l}\text { Difficult to } \\
\text { say }\end{array}$ & Important & $\begin{array}{l}\text { Very } \\
\text { important }\end{array}$ \\
\hline 1 & System functionality & 1.2 & 1.2 & 2.4 & 36.2 & 59.0 \\
\hline 2 & Ensuring data security & 1.2 & 2.4 & 2.4 & 22.9 & 71.1 \\
\hline 3 & $\begin{array}{l}\text { Quality and cost of support after } \\
\text { implementation }\end{array}$ & 1.2 & 2.4 & 8.4 & 54.2 & 33.7 \\
\hline 4 & $\begin{array}{l}\text { The system's compatibility with } \\
\text { other IT systems implemented in } \\
\text { companies }\end{array}$ & 1.3 & 6.0 & 8.4 & 47.0 & 37.3 \\
\hline 5 & System development options & 2.4 & 2.4 & 11.0 & 47.6 & 36.6 \\
\hline 6 & $\begin{array}{l}\text { Ensuring both adaptation to the } \\
\text { industry and system versatility }\end{array}$ & 2.4 & 10.8 & 12.0 & 49.4 & 25.4 \\
\hline 7 & $\begin{array}{l}\text { The cost of purchasing and } \\
\text { implementing the system }\end{array}$ & 2.4 & 8.4 & 19.3 & 47.0 & 22.9 \\
\hline 8 & $\begin{array}{l}\text { Reputation and experience of the } \\
\text { system provider }\end{array}$ & 2.4 & 13.4 & 18.3 & 47.6 & 18.3 \\
\hline 9 & $\begin{array}{l}\text { Substantive and technological } \\
\text { advancement of the system }\end{array}$ & 2.3 & 13.3 & 20.5 & 39.8 & 24.1 \\
\hline 10 & $\begin{array}{l}\text { Hardware and infrastructure } \\
\text { requirements of the system }\end{array}$ & 3.7 & 17.1 & 18.3 & 46.3 & 14.6 \\
\hline 11 & System implementation time & 2.4 & 14.5 & 32.5 & 32.5 & 18.1 \\
\hline 12 & $\begin{array}{l}\text { The option of paying an annual } \\
\text { subscription instead of } \\
\text { purchasing the system }\end{array}$ & 10.8 & 19.3 & 43.4 & 22.9 & 3.6 \\
\hline 13 & System location & 12.0 & 26.5 & 37.3 & 18.2 & 6.0 \\
\hline 14 & Novelty of system & 8.5 & 37.3 & 31.3 & 18.1 & 4.8 \\
\hline
\end{tabular}

For both groups of respondents, the most important criterion when choosing ERP/CRM systems in the SME sector was their functionality (Tables $2 \& 3$ ). In group 1 , all respondents indicated that this criterion is "important" or "very important", while in group $2 \sim 95.3 \%$ of the respondents chose such answers. The next criterion in terms of importance was the ability to ensure data security (over $96.0 \%$ in group $1 \& 93.0 \%$ in group 2 assessed it as "important" or "very important"). It is worth noting that the importance of other criteria varied in the two groups. For example, for people employed in companies responsible for system implementation, the next important factor was compatibility of the ERP/CRM with other implemented IT solutions (over $89.0 \%$ of respondents in group 1 indicated that this criterion is "important" and "very important") - Table 2, whereas SME workers valued higher the possibility of expanding the system (Table 3 ). 
Table 2. Importance of Criteria Taken Into Account When Choosing the ERP/CRM Class Systems, According to People Employed in Companies Responsible for System Implementation [\%].

\begin{tabular}{|c|c|c|c|c|c|c|}
\hline \multirow[t]{2}{*}{ Rank } & \multirow[b]{2}{*}{ Criterion } & \multicolumn{5}{|l|}{ Importance } \\
\hline & & $\begin{array}{l}\text { Completely } \\
\text { unimportant }\end{array}$ & $\begin{array}{l}\text { Not } \\
\text { important }\end{array}$ & $\begin{array}{l}\text { Difficult to } \\
\text { say }\end{array}$ & Important & $\begin{array}{l}\text { Very } \\
\text { important }\end{array}$ \\
\hline 1 & System functionality & 0.0 & 0.0 & 0.0 & 32.1 & 67.9 \\
\hline 2 & Ensuring data security & 0.0 & 3.6 & 0.0 & 25.0 & 71.4 \\
\hline 3 & $\begin{array}{l}\text { The system's compatibility with } \\
\text { other IT systems implemented in } \\
\text { companies }\end{array}$ & 0.0 & 3.6 & 7.1 & 50.0 & 39.3 \\
\hline 4 & System development options & 0.0 & 0.0 & 14.3 & 50.0 & 35.7 \\
\hline 5 & $\begin{array}{l}\text { Quality and cost of support after } \\
\text { implementation }\end{array}$ & 0.0 & 3.6 & 14.3 & 57.1 & 25.0 \\
\hline 6 & $\begin{array}{l}\text { The cost of purchasing and } \\
\text { implementing the system }\end{array}$ & 0.0 & 14.3 & 10.7 & 53.6 & 21.4 \\
\hline 7 & $\begin{array}{l}\text { Hardware and infrastructure } \\
\text { requirements of the system }\end{array}$ & 3.6 & 14.3 & 10.7 & 46.4 & 25.0 \\
\hline 8 & System implementation time & 0.0 & 10.7 & 21.4 & 46.5 & 21.4 \\
\hline 9 & $\begin{array}{l}\text { Ensuring both adaptation to the } \\
\text { industry and system versatility }\end{array}$ & 0.0 & 14.3 & 17.9 & 35.7 & 32.1 \\
\hline 10 & $\begin{array}{l}\text { Reputation and experience of the } \\
\text { system provider }\end{array}$ & 0.0 & 14.3 & 28.6 & 42.9 & 14.2 \\
\hline 11 & $\begin{array}{l}\text { Substantive and technological } \\
\text { advancement of the system }\end{array}$ & 0.0 & 17.9 & 35.7 & 32.1 & 14.3 \\
\hline 12 & $\begin{array}{l}\text { The option of paying an annual } \\
\text { subscription instead of purchasing } \\
\text { the system }\end{array}$ & 10.6 & 17.9 & 42.9 & 17.9 & 10.7 \\
\hline 13 & Novelty of system & 3.5 & 50.0 & 21.4 & 21.4 & 3.6 \\
\hline 14 & System location & 17.9 & 25.0 & 35.7 & 17.9 & 3.5 \\
\hline
\end{tabular}

It is also worth noting that the criteria that were of the least importance when choosing CRM/ERP systems in the SME sector were, in the opinion of two groups of respondents, respectively: the novelty of the system (nearly $54.0 \%$ of respondents in group $1 \& 44.2 \%$ in group 2 indicated that this criterion is "not important" or "completely unimportant"), the location of the system (approximately $43.0 \%$ of respondents in group 1 and $37.2 \%$ in group 2 indicated that this criterion is "not important" or "completely unimportant"), and the option of paying an annual subscription instead of purchasing the system (almost $29.0 \%$ of respondents in group $1 \& 27.9 \%$ in group 2 indicated that this criterion is "not important" or "completely unimportant"). 
Table 3. The Importance of Criteria Taken Into Account When Choosing ERP/CRM Class Systems, According to the Opinions of Employees of the SMEs in Which the Systems Were Implemented [\%].

\begin{tabular}{|c|c|c|c|c|c|c|}
\hline \multirow[t]{2}{*}{ Rank } & \multirow[b]{2}{*}{ Criterion } & \multicolumn{5}{|l|}{ Importance } \\
\hline & & $\begin{array}{l}\text { Completely } \\
\text { unimportant }\end{array}$ & $\begin{array}{l}\text { Not } \\
\text { important }\end{array}$ & $\begin{array}{l}\text { Difficult to } \\
\text { say }\end{array}$ & Important & $\begin{array}{l}\text { Very } \\
\text { important }\end{array}$ \\
\hline 1 & System functionality & 0.0 & 0.0 & 4.7 & 39.5 & 55.8 \\
\hline 2 & Ensuring data security & 0.0 & 2.3 & 4.7 & 27.9 & 65.1 \\
\hline 3 & System development options & 2.3 & 4.7 & 7.0 & 48.8 & 37.2 \\
\hline 4 & $\begin{array}{l}\text { The system's compatibility with } \\
\text { other IT systems implemented in } \\
\text { companies }\end{array}$ & 0.0 & 9.3 & 7.0 & 48.8 & 34.9 \\
\hline 5 & $\begin{array}{l}\text { Quality and cost of support after } \\
\text { implementation }\end{array}$ & 0.0 & 4.6 & 14.0 & 48.8 & 32.6 \\
\hline 6 & $\begin{array}{l}\text { Ensuring both adaptation to the } \\
\text { industry and system versatility }\end{array}$ & 2.3 & 9.3 & 9.3 & 55.8 & 23.3 \\
\hline 7 & $\begin{array}{l}\text { Substantive and technological } \\
\text { advancement of the system }\end{array}$ & 0.0 & 7.0 & 16.1 & 48.8 & 27.9 \\
\hline 8 & $\begin{array}{l}\text { Reputation and experience of } \\
\text { the system provider }\end{array}$ & 2.3 & 9.3 & 16.3 & 55.8 & 16.3 \\
\hline 9 & $\begin{array}{l}\text { The cost of purchasing and } \\
\text { implementing the system }\end{array}$ & 2.3 & 7.0 & 23.2 & 44.2 & 23.3 \\
\hline 10 & $\begin{array}{l}\text { Hardware and infrastructure } \\
\text { requirements of the system }\end{array}$ & 2.3 & 25.6 & 18.6 & 44.2 & 9.3 \\
\hline 11 & System implementation time & 2.3 & 11.6 & 44.2 & 30.2 & 11.7 \\
\hline 12 & $\begin{array}{l}\text { The option of paying an annual } \\
\text { subscription instead of } \\
\text { purchasing the system }\end{array}$ & 7.0 & 20.9 & 34.9 & 27.9 & 9.3 \\
\hline 13 & Novelty of system & 9.3 & 34.9 & 30.2 & 20.9 & 4.7 \\
\hline 14 & System location & 9.3 & 27.9 & 39.5 & 16.3 & 7.0 \\
\hline
\end{tabular}

In the next step of the analysis, the Spearman's rank correlation coefficient obtained for individual criteria in both groups was calculated. Ranks determined the position on which the criterion was found (in the study group) according to their importance. In the case of criteria that achieved an equal percentage of responses, the authors assigned them an arithmetic mean calculated from their subsequent numbers. Spearman's rank order correlation coefficients had a positive direction and assumed a value of $r_{s=} 0.88$ with statistical significance of $p=0.0128$. This means that there was a high correlation between the positions taken by individual criteria in both groups. In conclusion, 
there were no significant differences between the two groups of respondents in the perception of the importance of individual criteria determining the choice of ERP and CRM systems in the SME sector.

\section{Discussion and Conclusions}

Our literature review shows that the strategic choice of the ERP/CRM system should be based on a number of selection criteria. They cover a wide array of factors, ranging from financial, such as the price of the system and its implementation and maintenance, through technical, e.g. compatibility with other systems, implementation time, ease of use, security issues and, finally, factors connected with the vendor, i.e. its reputation, as well as experience and references. These conclusions are at least partially confirmed by the results of surveys completed in 2019 by 83 respondents with experience in the selection and implementation of ERP/CRM systems in SMEs in Poland, either from the "technical" point of view, i.e. the perspective of workers or owners of the IT system vendor, or that of the "business user", i.e. workers' or owners' of the SME that underwent implementation of such a system.

The analysis of the responses shows that the two most important criteria that should be taken into consideration while selecting an ERP/CRM system for an SME are: system functionality and the ability to ensure data security. There were no significant differences between ICT specialists and business users with regard to that. Their opinions varied slightly as far as other criteria were concerned: both groups stressed the importance of compatibility of ERP and CRM with other implemented IT solutions and the possibility of expanding the system, though "technical" respondents considered the former as more important whereas the "business" respondents valued higher the latter. Interestingly, respondents from neither group considered as very important such criteria as: the location of system or the option of paying an annual subscription instead of purchasing the system. They did not value the novelty factor high, either.

The most striking results to emerge from the data was that the cost of purchasing and implementing the system, though noteworthy, was not considered vital and was ranked lower than the quality and cost of support of the system after implementation, especially, which might be quite surprising, by the "business" respondents from SMEs. Contrary to findings from literature review, respondents did not place the reputation and experience of the vendor very high in the ranking, either. Furthermore, such "technical" aspects as hardware and infrastructure requirements of the system or system implementation time were not considered most significant. One can, therefore, draw a conclusion that such benefits which can be gained after the implementation as: usefulness, security and comfort of using the system are more important than the broadly understood costs of the project, i.e. the price to be paid or the time that has to be spent before the system is operational.

\section{Summary}

In the times of dynamically developing Knowledge-Based Economy, companies of all sizes have to resort to ICT technologies to stay competitive. It concerns also companies from the SME sector. A decision to implement an ERP or CRM system is not an easy one for decision-makers of SMEs because, as a rule, they do not have spare resources at their disposal - be it financial, human or IT 
expert knowledge. The aim of this study was, therefore, to make an attempt to define the most important selection criteria of the ERP/CRM class systems for SMEs. The main conclusions which can be derived from the literature studies and the research conducted among practitioners are that the main criteria that should be taken into account during the selection of the optimal ERP/CRM system are system functionality and the ability to ensure data security. The factors that seem to be least significant are the novelty of the system or its location.

This paper was meant as a pilot study. The main value of this study is the collection of opinions and suggestions of practitioners concerning the issues that decision-makers of SMEs should pay particular attention to while making a strategic decision of purchasing and implementing an ERP/CRM system. This paper has highlighted the significance of such criteria as system functionality and the ability to ensure data security, which should be placed higher in the decisionmaking hierarchy than the mere price of the system. The findings add to a growing body of literature on digitalization of SMEs. This research could be a useful aid for decision-makers of SMEs as they have limited access to expert knowledge in many of the areas their business activity is related to. ICT, a highly specialized and technical field is presumably one of them. Moreover, this study can be used as the basis for further research into success factors for selecting, implementing, using and developing ERP/CRM systems in SMEs. Its limitations include the lack of research on a larger research sample that would include a larger number of respondents, preferably from more than one country, as well as verification of workers and decision-makers' opinions with objective methods measuring the effectiveness of recommended and implemented solutions. The last limitation of this research was not covering issues related with the selection and implementation of other ICT systems.

\section{References}

Alanbay, O. (2005). ERP selection using expert choice software. Proceedings of the 8th International Symposium on Analytic Hierarchy Process, 1-10. https://pdfs.semanticscholar.org/254f/53a9d84152ba8345e9a205b1c735c00a98c4.pdf

Baki, B., \& Cakar, K. (2005). Determining the ERP package-selecting criteria. The case of Turkish manufacturing companies. Business Process Management Journal, 11(1), 75-86. https://doi.org/10.1108/14637150510578746

Ciski, P. (2015). ERP dla szybszego rozwoju (ERP for faster development). http://itmanager.pl/erp-dla-szybszego-rozwoju/

Cruz-Cunha, M. M., Silva, J. P., Gonçalves, J. J., Fernandes, J. A., \& Ávila, P. S. (2016). ERP selection using an AHP-based decision support system. Information Resources Management Journal, 29(4), 65-81.

Czekster, R. M., Webber, T., Jandrey, A. H., \& Marcon, C.A.M. (2019). Selection of enterprise resource planning software using analytic hierarchy process, Enterprise Information Systems, 13(6), 895-915. https://doi.org/10.1080/17517575.2019.1606285

Estdale, J., \& Georgiadou, E. (2018) Applying the ISO/IEC 25010 quality models to software product. In: Larrucea X., Santamaria I., O’Connor R., and Messnarz R. (Ed.) Systems, 
software and services process improvement. EuroSPI 2018. Communications in Computer and Information Science, 896, 492-503. Springer.

Eurostat (2018). Integration of digital technology by enterprises. https://ec.europa.eu/digitalsingle-market/en/integration-digital-technology

Główny Urząd Statystyczny (GUS, Statistics Poland) (2017). Społeczeństwo informacyjne w Polsce. Wyniki badań statystycznych z lat 2014-2018. (Information society in Poland. Results of statistical surveys in the years 2014-2018). https://stat.gov.pl/obszarytematyczne/nauka-i-technika-spoleczenstwo-informacyjne/spoleczenstwoinformacyjne/spoleczenstwo-informacyjne-w-polsce-wyniki-badan-statystycznych-z-lat2014-2018,1,12.html

Hamidi, H. (2015). A fuzzy decision making approach to enterprise resource planning system selection. Enterprise Iranian Journal of Operations Research, 6(1), 34-52.

Jankowski, P. (2015, August 12). Systemy klasy ERP coraz popularniejsze w małych i średnich przedsiębiorstwach (ERP class systems increasingly popular in small and medium enterprises). http://www.benchmark.pl/aktualnosci/systemy-erp-w-malych-firmach.html

Koch, S. (2001). ERP selection process in midsized and large organizations. Business Process Management Journal, 7(3), 251-257. https://doi.org/10.1108/14637150110392746

Madar (2019). CRM dla MŚP (CRM for SME). http://www.madar.com.pl/crm/msp.htm

Murias, A. (2019). Rozwiązanie CRM dla firm z sektora MŚP (CRM solution for companies from the SME sector). https://www.erp24.pl/crm-artykuly/rozwizanie-crm-dla-firm-zsektora-mp.html

Negacz, S. (2019, April 8). Ranking najlepszych systemów CRP dla MŚP 2019 (Ranking of the best CRP systems for SMEs 2019.). https://www.sellwise.pl/ranking-najlepszychsystemow-crm-2019/

QuickCRM (2019). 4 najważniejsze pytania o system CRM dla MŚP (The 4 most important questions about the CRM system for SMEs). https://quickcrm.pl/crm-dla-firm/

Reicher, R., \& Szeghegyi, Á. (2015). Factors affecting the selection and implementation of a customer relationship management (CRM) process. Acta Polytechnica Hungarica, 12(4), 183-200.

Stankovska, I., Josimovski S., \& Edwards C. (2016). Digital channels diminish SME barriers: The case of the UK. Economic Research-Ekonomska Istraživanja, 29(1), 217-232. 


\section{Appendix - Survey Questions}

The survey questions were written in Polish by the authors of this study. They were translated into English by the authors of the study for the listing in the paper. The translation was validated by a professional translator.

\section{Respondent's general data}

1. Gender: $\mathrm{M}$ or $\mathrm{F}$

2. Education:

3. Position/role during the implementation of the CRM/ERP system in SMEs in Poland:

- Technical employee of the external company implementing the system

- Owner/decision-maker of the external company implementing the system

- Employee of the SME in which the system was implemented

- The owner/decision-maker of the SME in which the system was implemented:

- Other (what?)

4. Work experience in work related to the implementation/use of IT systems:

Up to 1 year

$1-5$ years

Over 5 years

5. Industry sector(s) of the SME(s) in which the IT system(s) was/were implemented:

\section{Research questions}

1. On a scale of 1-5, evaluate the importance of the following criteria that should be taken into account when choosing a CRM/ERP system for SMEs:

1 unimportant 2 of little importance 3 difficult to say 4 important 5 very important

a. System functionality

b. The system's compatibility with other IT systems implemented in companies

c. The cost of purchasing and implementing the system

d. System implementation time

e. System development options

f. Reputation and experience of the system provider

g. The option of paying an annual subscription instead of purchasing the system

h. Ensuring data security

i. Quality and cost of support after implementation

j. $\quad$ Novelty of system

k. Substantive and technological advancement of the system

1. Hardware and infrastructure requirements of the system

m. Ensuring both adaptation to the industry and system versatility

n. System location 


\section{Authors Biographies}

Malgorzata Cieciora, Ph.D. has spent more than 25 years in the academic community. She earned a Ph.D. in Economics from The University of Gdańsk in 2003. She has been working in the Polish-Japanese Academy of Information Technology in Warsaw (formerly Polish-Japanese Institute of Information Technology) since it was founded in 1994. Currently Dr. Cieciora is the Dean of the Faculty of Information Management. Her research is focused on quality management, business process management and project management in the tertiary education institutions. She has published numerous papers and one book dedicated to management in the academic environment.

Wiktor Bołkunow, Ph.D. is a lecturer on economics at the Warsaw School of Economics, Poland. He received his Ph.D. in economics from the Warsaw School of Economics in 2008. He is the author of over 50 scientific articles. His main research areas are entrepreneurship, economic policy and development of small and medium-size enterprises.

Piotr Pietrzak, Ph.D. is an adjunct professor of Management Institute at Warsaw University of Life Sciences. His main areas of interest include efficiency of public sector institutions, public management, performance measurement, Balanced Scorecard. He is the author of over 50 articles and 3 books.

Piotr Gago, M.Sc. is a Ph.D. student and an assistant professor at the Faculty of Computer Science at the Polish-Japanese Academy of Information Technology in Warsaw. He obtained a Master of Science degree in Computer Science with rector's distinction in two specializations: warehouses and databases. He is the research supervisor of the Project Management Student Research Club.
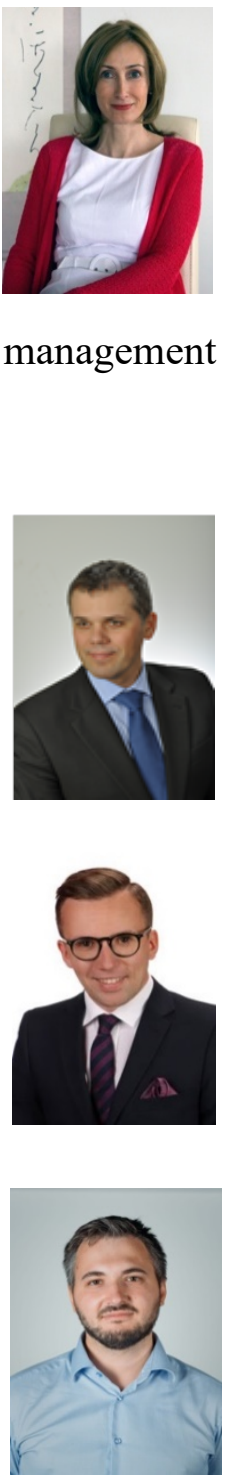